\title{
A TENTATIVA DE SUICÍDIO NA ADOLESCÊNCIA: um olhar psicanalítico
}

DOI: 10.22289/2446-922X.V8N1A8

\author{
Matheus Colombari Caldeira ${ }^{1}$ \\ Luciano Aparecido Pereira Junior \\ Regina Célia de Souza Beretta \\ Antônio Cézar Peron \\ Carlos Alberto da Costa
}

\section{RESUMO}

A tentativa de suicídio evidencia a não consumação do ato de tirar a própria vida, dando à tentativa e ao suicídio uns lugares sintomáticos diferentes. O objetivo deste estudo foi discutir sobre a tentativa de suicídio em adolescentes na contemporaneidade e sua relação direta com a cultura, por meio da Psicanálise. A pesquisa bibliográfica exploratória foi realizada nas plataformas SciELO, Google Acadêmico e PePSIC-BVS, sendo selecionados cinco artigos datados de 2017-2021, bem como livros contidos na literatura e dados disponíveis em sites e cartilhas do governo brasileiro. Os descritores utilizados para a pesquisa foram: Adolescente, Suicídio e Psicanálise. A análise de conteúdo realizada teve como premissa o contexto psicanalítico enquanto referencial teóricometodológico, além da compreensão dos impactos sociais gerados pela temática. A influência sociocultural interfere diretamente na temática do suicídio, frente ao tabu que é falar sobre a morte e diante do suicídio, como sintoma de um adoecimento social e dificuldades de espaços de escuta dos adolescentes e políticas públicas de atenção a adolescência. Por fim, é preciso compreender e articular ações, no âmbito das políticas públicas, bem como da clínica psicanalítica, que se disponham a atuar e agir frente às realidades sociais e culturais que envolvem as tentativas de suicídio e os suicídios consumados - uma compreensão ampla das realidades vividas e da integralidade (biopsicossocial, cultural e espiritual) dos sujeitos.

Palavras-chave: Adolescente; Suicídio; Psicanálise.

\section{ADOLESCENT SUICIDE ATTEMPTED: a psychoanalytic view}

\section{ABSTRACT}

The suicide attempt evidences the non-consummation of the act of taking one's own life, giving the attempt and the suicide a different symptomatic place. The objective of this study was to discuss suicide attempt in adolescents in contemporary times and its direct relationship with culture, through psychoanalysis. The exploratory bibliographic research was conducted in the SciELO, Google Scholar and PePSIC-BVS platforms, and five articles dated 2017-2021 were selected, as well as books contained in the literature and data available on Brazilian government websites and primers. The descriptors used for the search were: Adolescent, Suicide, and Psychoanalysis. The content analysis carried out was based on the psychoanalytic context as a theoretical and methodological

\footnotetext{
${ }^{1}$ Endereço eletrônico de contato: mmatheuscaldeira_@hotmail.com

Recebido em 11/10/2021. Aprovado pelo conselho editorial para publicação em 13/01/2022.
}

Rev. Psicol Saúde e Debate. Jan., 2022:8(1): 125-137. 
reference, besides the understanding of the social impacts generated by the theme. The sociocultural influence directly interferes in the suicide theme, due to the taboo of talking about death and suicide as a symptom of a social illness and the difficulties of listening spaces for adolescents and public policies for adolescent care. Finally, it is necessary to understand and articulate actions, within the scope of public policies, as well as psychoanalytic clinics, which are willing to act and respond to the social and cultural realities involving suicide attempts and completed suicides - a broad understanding of the realities experienced and the integrality (biopsychosocial, cultural, and spiritual) of the subjects.

Keywords: Adolescent; Suicide; Psychoanalysis.

\section{INTENTO DE SUICIDIO ADOLESCENTE: una mirada psicoanalítica}

\section{RESUMEN}

La tentativa de suicidio evidencia la no consumación del acto de quitarse la vida, dando al intento y al suicidio un lugar sintomático diferente. El objetivo de este estudio fue discutir la tentativa de suicidio en adolescentes en la época contemporánea y su relación directa con la cultura, por medio del Psicoanálisis. La investigación bibliográfica exploratoria fue realizada en las plataformas SciELO, Google Academico y PePSIC-BVS, siendo seleccionados cinco artículos con fecha 20172021, así como libros contenidos en la literatura y datos disponibles en sitios web del gobierno brasileño y cartillas. Los descriptores utilizados para la búsqueda fueron: Adolescente, suicidio y psicoanálisis. El análisis de contenido realizado se basó en el contexto psicoanalítico como referencia teórica y metodológica, además de la comprensión de los impactos sociales generados por el tema. La influencia sociocultural interfiere directamente en el tema del suicidio, ante el tabú que supone hablar de la muerte y el suicidio como síntoma de una enfermedad social y las dificultades de los espacios de escucha para los adolescentes y las políticas públicas de atención a los mismos. Finalmente, es necesario comprender y articular acciones, en el ámbito de las políticas públicas, así como de las clínicas psicoanalíticas, que estén dispuestas a actuar y responder a las realidades sociales y culturales que involucran los intentos de suicidio y los suicidios consumados una amplia comprensión de las realidades vividas y la integralidad (biopsicosocial, cultural y espiritual) de los sujetos.

Palabras clave: Adolescente; Suicidio; Psicoanálisis.

\section{INTRODUÇÃO}

Durkhein (2000) aponta que o adoecimento está intimamente conectado ao período em que se vive, além disso, relata que podemos observar o surgimento de novas patologias e o período de sua emergência. Não distante dessa compreensão, Freud (1893-1895/2016), em Estudos Sobre a Histeria, apontava que o sintoma emerge como retorno de um conteúdo traumático experienciado pelo sujeito. No campo do suicídio questiona-se o que tem tanta energia para dominar a pulsão de vida, a decepção da libido ou o Eu que se renuncia por motivos próprios (Freud, 1910/2013). Para Lacan (1962-1963/2005) algo que pode tomar o sujeito é a angústia que retorna presentificando o 
objeto a, resto que fica fora da cadeia significante e ao emergir cria a certeza, que retira o sujeito da cena (Brunhari, 2014).

O suicídio movimenta questões morais, religiosas e sociais, vindo a se tornar uma questão não somente do indivíduo, mas também de saúde pública (Teixeira, Souza \& Viana, 2018). No ano de 2016 houve aproximadamente 800 mil mortes por suicídio no mundo, uma pessoa a cada 40 segundos se suicida, é a segunda principal causa de morte de jovens entre 15 a 29 anos, segundo o Relatório de Estatísticas Mundiais de Saúde (Who, 2018). Quando se abordam as tentativas de suicídio, estima-se que, para cada suicídio consumado, ocorra cerca de 20 tentativas, o que retrata um cenário de aproximadamente 20 milhões ocorrências por ano no mundo (Cfp, 2013). A tentativa de suicídio é um alerta para o cuidado com a saúde mental. Deste modo, é um indicativo que deve ser observado, a fim de que se possam encontrar meios que auxiliem no atendimento e acompanhamento desses adolescentes (Who, 2014).

No Brasil, há a Rede de Atenção Psicossocial (RAPS), instituída pela Portaria MS/GM no 3.088, de 23/12/2011 que cuida de "pessoas com sofrimento ou transtorno mental e com necessidades decorrentes do uso de crack, álcool e outras drogas, no âmbito do Sistema Único de Saúde (SUS)" (Brasil, 2011, p.1).

Os Centros de Atenção Psicossocial (CAPS) fazem parte desse sistema, sendo direcionado os casos infantis e de adolescentes ao CAPSi, voltado ao cuidado de transtornos mentais graves e persistentes, além de substâncias químicas, atendendo cidades de pelo menos 70 mil habitantes (Brasil, 2017).

No estudo realizado por Zanette et al. (2020) foram apontadas algumas das faces da tentativa de suicídio por parte de adolescentes em acompanhamento no serviço de CAPSi. Pontuam que o suicídio é um problema de saúde pública e que demanda por equipamentos e serviços de saúde que possam atender tais demandas, e que estes dispositivos não se encontram em todos os territórios.

O Ministério da Saúde aponta que em 2006 havia 75 CAPSi e em 2014 o número foi elevado a 201. Embora haja uma crescente, estados como Acre, Roraima e Tocantins não possuem CAPSi habilitados (Brasil, 2015).

Podem ser observados comportamentos de automutilação, tristeza constante e uma vivência solitária. O essencial é que as pessoas ao redor, assim como os profissionais da rede de atenção em saúde, se atentem aos comportamentos dos adolescentes a fim de que estes alertas possam ser percebidos $O$ suicídio ou a tentativa pode estar atrelada a possível trauma que tenha ocorrido com o indivíduo, seja na infância ou até mesmo, na adolescência. Portanto, serviços como o CAPSi que possam acolher sobre o sofrimento de crianças e adolescentes são observados como fundamentais ao cuidado em saúde mental (Zanette et al., 2020). 
Macedo e Werlang (2007) destacam que a vivência traumática além de se imprimir no sujeito, passa a ser um processo de repetição constante. Esta repetição se dá pelo campo que irrompe da Tiquê, parte real da repetição e não simbolizável (Lacan, 1964/2008). Entretanto, é na escuta qualificada que há uma possibilidade de apreensão da repetição significante e elaboração do trauma, em que o sujeito coloca em palavras o que viria a ser ato, dando contorno à angústia.

Carvalho (2014, p. 145) descreve que o ser humano, como ser falante, é o único que atenta contra a própria vida, fazendo da morte uma alternativa.

O homem suporta a vida pela possibilidade que dispõe de matar-se. A morte é o que torna a vida possível. A vida é real e a morte é simbólica, e se o real é o impossível, viver é o exercício da impossibilidade. E o suicídio é uma escolha capaz de dar um significado à vida quando ela chega ao limite da impossibilidade.

Todavia, é por ser uma dificuldade de elaboração que a compreensão dos fatores que relacionados ao suicídio ainda são um enigma, porém, é no mito do sujeito (Lacan, 1953/1987) que pode se encontrar indícios da significação do adoecimento.

O objetivo deste estudo, enquanto revisão bibliográfica, foi discutir sobre a tentativa de suicídio em adolescentes na contemporaneidade e sua articulação com o tabu a partir da psicanálise.

\section{METODOLOGIA}

O presente trabalho é composto de reflexões sobre a tentativa de suicídio em adolescentes a partir de pesquisa bibliográfica exploratória em livros e artigos psicanalíticos de vertente lacaniana. Na pesquisa bibliográfica é feita uma investigação de documentos publicados e posteriormente analisados (Prodanov \& Freitas, 2013).

A pesquisa foi realizada nas plataformas SciELO, Google Acadêmico e PePSIC-BVS, sendo selecionados cinco artigos, bem como livros contidos na literatura e dados disponíveis em sites e cartilhas do governo brasileiro. Os descritores utilizados para a pesquisa foram: Adolescente, Suicídio e Psicanálise.

Como critérios de inclusão, foram selecionados os artigos datados do período entre os anos de 2017 e 2021, bem como a correlação dos estudos entre os descritores e o objetivo de discussão proposto. Os estudos que não obedeciam a estes critérios, foram excluídos. Os dados coletados foram lidos, inicialmente, pelos resumos e posteriormente de forma integral, até a redução para o número final $(\mathrm{n}=5)$.

A análise de conteúdo realizada teve como premissa o contexto psicanalítico enquanto referencial teórico-metodológico, além da compreensão dos impactos sociais gerados pela 
temática. Deste modo a Psicanálise se baseia na premissa do inconsciente como organizador da nossa experiência subjetiva (Garcia-Roza, 2009). E foi por meio desta teoria, que se levantou a reflexão da tentativa de suicídio na adolescência, com a premissa de que a fatores desconhecidos pelo Eu, influenciam neste processo.

\section{DESENVOLVIMENTO}

\subsection{Adolescência, cultura e sociedade}

A adolescência, período característico de algumas civilizações que demarcam os limites entre a infância e a vida adulta, é atravessado por transformações físicas, processos de mudanças no âmbito psicológico, familiar, social e cultural (Papalia \& Feldman, 2013). No período da puberdade, o sujeito começa a despertar o aspecto sexual, como manifestação das experiências vividas na infância. Viola e Vocaro (2018, p. 9) salientam que é necessário retomar "a hipótese de uma operação da adolescência que articula a reinscrição simbólica do sujeito com o confronto com o real do sexo, de maneira que se inaugura uma nova forma de se relacionar com o saber".

A adolescência, enquanto etapa do processo de desenvolvimento humano, deve ser observada tanto biologicamente, quanto de maneira psicossocial e cultural. Sobre o adolescente, além das transformações hormonais e corporais, se estabelece também a perda da infância e a transição para o "ser adulto". Socialmente, ser adolescente, em especial no mundo capitalista, é vivenciar exigências como as que são enfrentadas pelos adultos, o que vai de encontro com esta etapa da vida (não é mais criança e ainda não é um adulto).

Dolto (2004) estabelece a adolescência como uma fase de mutação e transformação, nos aspectos biopsicossociais e culturais do adolescente, num processo de crescimento e transição que acontece até os 25 anos, mas que é abordado de diversas formas por estudiosos no mundo. $O$ Estatuto da Criança e do Adolescente (ECA), por exemplo, estabelece a adolescência no período entre os 12 e 18 anos (Brasil, 1990).

O ser adolescente pode ser compreendido como um "estado de adolescência", que vai se prolongando ou se reduzindo na medida em que os adultos projetam sobre estes sujeitos as cobranças, características e comportamentos que são socialmente aceitos e impostos enquanto limites de exploração. O adulto deve executar um papel de mediador entre o indivíduo e o mundo, no que concerne o processo de responsabilização, de reconhecimento das leis e limitações e de sua constituição saudável, enquanto pessoa de direitos e de desejos (Dolto, 2004).

Oliveira e Hanke (2017) destacam que as influências sociais e o mundo impactam diretamente o sujeito e sua pulsão, correlacionado a cultura e o inconsciente em mútua influência.

Neste sentido, Ons (2018, p. 214-215) afirma que: 
Muitas vezes, o que para um sujeito antes podia ser um pensamento, uma conduta esporádica ou uma fantasia, logo se torne uma chave que responde ao que seria sua real identidade. E, quando um sujeito está desorientado algo muito comum nestes tempos -, agarra-se muito mais àquilo que lhe dará um suposto ser.

Esse suposto ser é apresentado por Bauman (2001, p. 184) como frágil, uma combinação "da falta de garantias (de posição, títulos, sobrevivência), da incerteza (em relação à sua continuação e estabilidade futura) e da insegurança (do corpo, do eu e de suas extensões: posses, vizinhança e comunidade)".

E neste contato com a cultura que coloca o sujeito em uma posição de escolha, "a civilização exige do sujeito uma renúncia pulsional. Todo laço social é, portanto, um enquadramento da pulsão, resultando em uma perda real de gozo" (Quinet, 2009, p. 17). No entanto, esta perda de gozo não é admitida pelo sujeito, então opta-se por uma certeza distorcida, que busca evitar a angústia, mas evidenciando-a perante o não saber. Afasta-se de qualquer posição possível a se ocupar, pois todas oferecem perdas.

Como aponta Ons (2018, p. 172), “aquilo que foi perdido ganha um valor único, irrecuperável. Bastam como exemplos os suicídios de alguns sujeitos ao perder o emprego ou [...] por esses adolescentes certos da futilidade da existência".

Ao passo que o ato simbólico opera um corte simbólico no real, a passagem ao ato subtrai o sujeito do registro do simbólico, para situá-lo no lugar do real: o sujeito deixa de ser um significante que se representa por meio da associação com outro significante, para se tornar aquilo que dele escapa à simbolização, identificado com o objeto a (Alberti, 2009, p. 84).

Assim, a tentativa do suicídio como contato com o Real busca o gozo absoluto, paradoxalmente exigente e inalcançável, em que o desejo deixa de funcionar, abrindo as portas para a passagem ao ato. Viola e Vorcaro (2018, p. 9) apresentam como característica própria do momento da adolescência essa deriva dada pela ausência de referências, "vulnerável a um gozo que não é suficientemente contido. Esse corpo é constantemente testado em seus limites".

E para "capturarmos" este corpo, Zafiropoulos (2018) nos orienta pelos olhos de Lacan, que para além do biológico, do orgânico, é preciso conferir um sujeito submetido à lei, o qual se faz em um campo simbólico, e o sintoma lhe exige o que ele próprio desconhece. Esta lei que se inscreve determina que "é impossível que o sujeito marcado pela função paterna escape do drama do malestar na civilização" (Alberti, 2009, p. 215).

Entretanto, Castro (2018, p. 235) nos apresenta que "o aspecto abstrato do pai simbólico está relacionado à forma de atribuição da paternidade", o que cabe pensar que as figuras que elegemos como representantes, que fazem a função do Nome-do-Pai, estão sendo destituídas de 
sua posição. É preciso acentuar que as mudanças familiares e sociais têm caracterizado novas formas de se viver, e que a função paterna não cabe somente à figura do pai, mas a todo aquele que assume este papel frente ao sujeito, a mãe, a avó, o avô, entre outros. O Nome-do-Pai é foi um conceito criado por Lacan em 1953 para articular esses significantes da função (Roudinesco, 1998, p. 541).

Esse simbolismo possibilita a saída do gozo fornecido pela função materna, deste Outro, reposicionando o sujeito perante a Lei e ao seu desejo (Fink, 2018). É oportuno apresentar que o Nome-do-Pai não é passível de desmonte e que é impossível matá-lo, uma vez que está morto. Ele detém uma estrutura primordialmente subjetiva, e como pondera Lacan (2008, p. 149) "é justamente por só se manter como simbólico, que o Nome-do-Pai é o eixo em torno do qual giram todos os campos da subjetividade".

É possível destacar dois momentos desta conceituação, primeiramente há a permanência ou não do significante paterno, orientando o sujeito. No segundo momento considera a multiplicidade de ordenadores com propósito de amarração do sujeito, Nomes-do-Pai, no plural. Desta forma, há a ampliação da clínica não mais centrada na castração, mas dirigida pela ordem do Real (Heinemann \& Chatelard, 2012). Lacan (2008, p.148) pontua que em um corpo que somente goza "está perfeitamente claro que o gozo se distingue absolutamente da Lei".

O adolescente objetivando não perder e alcançar o ápice de suas possibilidades, orienta-se pelo gozo, sem ao menos adotar as consequências do desejo, apresenta-nos a evitação da Lei, em que nenhuma tentativa de simbolização é assumida com veemência. O Nome-do-Pai é substituído pelo gozo pleno, em que fica evidente a fragilidade com que este se constitui no simbólico. Neste sentido, a própria ideia de Lei se desfaz, ao passo que, o que é proibido perde potência e o "não matarás", que até então seria uma proibição, já não é capaz de fazer fronteira no sujeito, "quanto mais se obturar o desejo, tanto mais se afirmará o sintoma" (Ons, 2018, p. 226).

\subsection{O tabu e a tentativa de suicídio}

O tabu é um termo conjecturado na Polinésia, podendo ser compreendido de duas maneiras, como sagrado e como proibição (Freud, 1912-1913/2012). Ao longo da história se demonstrou eficaz em interditar o desejo, onde o objeto como mana (vínculo social), representado pelo Totem, distância o comum e o profano de alcançá-lo, entretanto "tudo o que é tabu parece despertar o desejo de violá-lo, pois o proibido incita a transgressão" (Pagés, \& Ávila, 2003, p. 76).

A transgressão gera culpa nas neuroses, e ao sujeito cabe a prática de atos de expiação, a fim de que não seja atingido pelos efeitos punitivos de sua ação. Determinadas ações carregam consigo características de tabu, que são estabelecidas de forma cultural, condicionadas à moral social. A tentativa de suicídio rompe com estes valores morais e sociais, o que corresponde a 
violação de um tabu, criando um temor no sujeito que transgride. A partir daí, é evitado falar sobre a atitude e o contato com o indivíduo transgressor, reduzindo imaginariamente a contaminação e a propagação dos atos transgressores.

Minois (2018, p. 191) apresenta que, no fim do Renascimento, a incitação à transgressão ganha espaço pela perda da força da religião. Indaga, "o que podem as ameaças de inferno, quando se acredita que a vida é pior do que o inferno? O suicídio desaparecerá quando desaparecerem suas causas, ou seja, quando a Terra for um paraíso e a felicidade reinar absoluta". Defrontamonos com o impasse de que havendo ou não o discurso religioso, se mantém presente a tentativa e o suicídio.

David Phillips (1974) aborda em seu artigo intitulado "The influence of suggestion on suicide: Substantive and theoretical implications of the Werther effect", o efeito da comunicação do suicídio e sua influência em outras tentativas de suicídio. O efeito Werther, assim chamado por Phillips, é retirado de uma obra de 1774 , do autor alemão Johan Wolfgang Von Goethe, nomeada "O sofrimento do jovem Werther". Esta literatura conta a história de um jovem que se apaixona por uma mulher casada e na impossibilidade de viver esta paixão retira sua própria vida. É desenvolvida a ideia de que suicídios sucessores podem preceder a um suicídio amplamente divulgado (Phillips, 1974). O suicídio por contágio é uma realidade encontrada na pesquisa de Loureira, Moureira e Sachsida (2013), que entre 1980 e 2009 identificou a mídia como o terceiro principal fator motivador do suicídio no Brasil.

Entretanto, a afirmação da hipótese por contágio apresenta-se muito simplista, considerando os aspectos históricos, sociais e singulares dos sujeitos (Hwang \& Kovács, 2019). Em seus estudos sociológicos, Durkheim (2000, p. 141) evidenciava que a repetição dos suicídios não teria relação com a propagação por contágio, ou seja, os suicídios não seriam consequência da divulgação, mas se dariam por meio de uma "resolução coletiva", além do fato de que o sujeito que quebra o tabu se transforma em tabu, se colocando em lugar privilegiado perante o coletivo (Freud, 1912-1913/ 2012). A resolução coletiva pode ser destacada por meio da ligação, por parte dos adolescentes, a uma sociedade e cultura adoecida, de modo que as suas saídas sintomáticas podem personificar certa similaridade com este adoecimento (Durkheim, 2000). O sintoma não é somente do indivíduo, mas sim um sintoma social.

O tabu não se aplica somente sobre o suicídio, a morte em si é um tabu. Dolto (2004), uma pediatra e psicanalista francesa, destaca que a prevenção para o suicídio é falar sobre a morte e a presença dela no cotidiano da vida humana. Falar sobre o suicídio ainda é motivo de dúvidas e medo de diversas pessoas e profissionais, mas "quando não existe um espaço, público ou privado, para que esses sentimentos possam ser falados, compartilhados e esclarecidos, a elaboração desse ato se torna muito mais difícil" (Bteshe, 2018, p. 254). A mídia tem papel importante na vida das pessoas, pode influenciar as pessoas, sendo um fator de risco se utilizada de maneira 
inadequada em relação ao suicídio, ou pode vir a ser uma grande articuladora de informações, atuando na prevenção e promoção de saúde (Hwang \& Kovács, 2019).

Mediante isso, não devemos silenciar a temática do suicídio em meios midiáticos, mas ampliar a discussão responsável que visa o diálogo como meio de prevenção e de escuta às demandas sociais pertinentes a esta temática que encontram limites na mídia, devendo ser a partir daí demanda de um olhar clínico especializado. Na pesquisa de Sousa, Ferreira e Galvão (2020), nota-se a importância de ampliar os meios de tratamento fornecidos pelos serviços de saúde, na estruturação das políticas públicas e redes de saúde mental.

Dolto (2004), continuando sua explanação, salienta que se for adotada uma psicoterapia do silêncio e da escuta, dificilmente $\mathrm{o}$ isolamento instalado será rompido. $\mathrm{E}$ que tudo que perpassa pelo campo do falar, da palavra, se torna humano, diferente do comportamento. Caso seja instalado o contrário disto, prevalecerá a intolerância e com ela, a ausência de humanidade, o desumano.

É essa linguagem interior [que surge por meio da expressão e da fala] que importa compreender, mas tudo depende do psicoterapeuta e de sua maneira de abordar a criança [ou o adolescente]. E quando fazemos uma criança pequena [ou um adolescente] dizer seu desejo de morrer, tudo muda (p. 111).

Neste sentido, falar sobre a morte se torna essencial frente à cultura e a sociedade atual. Quebrar este paradigma e falar sobre a morte, seja nas escolas ou nos espaços públicos, torna a tarefa de prevenção mais efetiva. A fala, mais do que prevenção, se torna promoção da saúde, permite ao sujeito o autocuidado, o autoconhecimento e a autonomia.

\subsection{O gozo e a função do supereu}

O suicídio, assim como o que deriva dele, reflete as nuances da singularidade do sujeito em contato com a cultura. Em tempos de mudanças constantes, lutas e vulnerabilidades sociais persistentes, as mazelas da realidade se intensificam frente a um sistema que preza pelo capital e pela renda, mas que pouco se preocupa com os sujeitos, a qualidade de vida e suas angústias constantes. O ser humano é sempre desejante e motivado pela falta, um ser em busca, mas que sempre viverá a insatisfação de ser que é utilizada politicamente pelo capitalismo (Žižek, 2009).

$\mathrm{Na}$ tentativa do suicídio, o atravessamento agride a própria lei, emergindo então o gozo - o sujeito encontra um certo tipo de satisfação, mesmo que isto custe a própria vida. O gozo é aquilo que aparece fora do discurso do sujeito, que é ordenado pelo significante, o gozo está do lado do Real (Valas, 2001). Lacan define três modalidades de gozo, o gozo do ser, o fálico e o do Outro (Braunstein, 2007).

Ao pensar a tentativa de suicídio na relação com o gozo fálico, esse posterior a entrada na linguagem e aceitação da Lei (Nome-do-Pai), o modo de extrair sua satisfação seria pela fala, da 
ficção construída após o retorno da tentativa. A fantasia passa a ter função central, apontando para o sujeito, onde "o desejo de morte, que põe em cena a fantasia de morrer do sujeito, é na verdade a sua vontade de abolir-se para eternizar-se no ser, para passar para a memória, para ser amado e desejado" (Valas, 2001, p. 25). É articulado um jogo de manter-se vivo e morto na fantasia, na transição entre a vida e a morte, de possuir o domínio total e, portanto, ser livre da castração, assumindo ele próprio o lugar de Mito, que se orienta pelo gozo do Outro, onde já afirmava Lacan "que a esperança absoluta pode conduzir ao suicídio, porque o que vale é só o que se espera" (Ons, 2018, p. 172).

Neste contexto, o Supereu interfere diretamente, ele exige a renúncia de um desejo que é proibido (a lei proíbe o gozo), o que defende o Eu para que este se mantenha íntegro e não se fragmente, mas se outro modo de funcionar aponta sua tirania, que condena, que ordena e que inibe, no fim ele próprio é responsável pela exigência do gozar (Nasio, 1997). É no caráter desmedido da exortação que ocorrem as realizações brutais de desejos homicidas e suicidas, frente a um supereu tirânico, que age de forma violenta e mórbida. O supereu, que se instala como lei, a fim de proteger o sujeito, em seus extremos acarreta condições que ultrapassam o sentido da culpa.

\section{CONSIDERAÇÕES FINAIS}

O estudo buscou refletir as relações entre o sujeito, a tentativa de suicídio e o tabu, apontando para como a articulação entre esse Real das mudanças na adolescência e a ascensão mítica imaginária podem interferir diretamente em como o sujeito se posiciona em relação no gozo. Além disso, as discussões demonstraram a importância de falar sobre o suicídio, para repensar as problemáticas para este modo de adoecer. O adolescente está aprisionado na insistência da morte, no lado do gozo, enquanto viver é assumir a castração e toda sua impotência, sem perceber que não se pode gozar morto.

Por fim, ainda há muito que se falar e se compreender a respeito do suicídio e da relação dos sujeitos com a morte. Isto implica em abrir espaços ativos para a discussão sobre as temáticas e a saída da clínica, para espaços onde a informação possa chegar com maior facilidade, com o sujeito e com o coletivo, agindo diretamente na sociedade que adoece seus sujeitos.

O artigo não pretende esgotar ou reduzir o tema aos aspectos abordados aqui, mas estimular outros estudos que venham abordar a temática, que é pertinente e atual. 


\section{REFERÊNCIAS}

Alberti, S. (2009). Esse sujeito adolescente. Rio de Janeiro: Rios Ambiciosos/ Contracapa.

Bauman, Z. (2001). Modernidade Líquida. Rio de Janeiro: Zahar.

Braunstein, N. (2007). Gozo. São Paulo: Escuta.

Brunhari, M. V., Darriba, V. A. (2014). O suicídio como questão: melancolia e passagem ao ato. Psicologia Clínica [online], 26(1), 197-213. https://doi.org/10.1590/S0103-56652014000100013

Brasil. (1990). Estatuto da Criança e do Adolescente - Lei № 8.069, de 13 de julho de 1990. Brasília: Presidência da República.

Brasil. (2015). Saúde Mental em Dados - 12, ano 10, no 12. Informativo eletrônico. Brasília: Ministério da Saúde. $\quad$ Recuperado em https://www.mhinnovation.net/sites/default/files/downloads/innovation/reports/Report 12edicao-do-Saude-Mental-em-Dados.pdf

Brasil. (2011). Institui a Rede de Atenção Psicossocial para pessoas com sofrimento ou transtorno mental e com necessidades decorrentes do uso de crack, álcool e outras drogas, no âmbito do Sistema Único de Saúde (SUS). Brasília: Ministério da Saúde. Recuperado em https://bvsms.saude.gov.br/bvs/saudelegis/gm/2011/prt3088 23122011 rep.html

Brasil. (2017). Centro de Atenção Psicossocial. Brasília: Ministério da Saúde. Recuperado em https://www.gov.br/saude/pt-br/acesso-a-informacao/acoes-e-programas/centro-de-atencaopsicossocial-caps

Bteshe, M.(2018). O suicídio na mídia: reflexões para o cuidado em saúde mental. RECIIS - Revista Eletrônica de Comunicação, Informação e Inovação em Saúde, 12(3), 252-257.

Carvalho, S. (2014). A morte pode esperar? Clínica psicanalítica do suicídio. Salvador: Associação Campo Psicanalítico.

Castro, J. C. L. de. (2018). Père-Version: A Relativização do Nome-Do-Pai. Ágora Estudos em Teoria Psicanalítica [online], 21(2), 233-243. https://doi.org/10.1590/S1516-14982018002009

Conselho Federal de Psicologia (CFP). (2013). O suicídio e os desafios para a Psicologia. Brasília: CFP.

Dolto, F. (2004). A Causa dos Adolescentes. Aparecida: Ideias \& Letras.

Durkheim, E. (2000). O suicídio: estudo de sociologia. São Paulo: Martins Fontes.

Fink, B. (2018). Introdução clínica à psicanálise lacaniana. Tradução de Vera Ribeiro. (1. Ed.). Rio de Janeiro: Zahar.

Freud, S. (2016). Obras completas, volume 2: Estudos sobre histeria (1893-1895) em coautoria com Josef Breuer. São Paulo: Companhia das Letras. (Originalmente publicado em 1893-1895).

Freud, S. (2016). Introdução e conclusão de um debate sobre o suicídio. In S. Freud, Obras completas, volume 9: Observações sobre um caso de neurose obsessiva ["O homem dos ratos"], uma recordação de infância de Leonardo da Vinci e outros textos (1909-1910). São Paulo: Companhia das Letras. (Originalmente publicado em 1910).

Rev. Psicol Saúde e Debate. Jan., 2022:8(1): 125-137. 
Freud, S. (2012). Totem e tabu. In S. Freud, Obras completas, volume 11: Totem e tabu, contribuição à história do movimento psicanalítico e outros textos (1912-1914). São Paulo: Companhia das Letras. (Originalmente publicado em 1912-1913).

Garcia-Rosa, L. A. (2009). Freud e o inconsciente. Rio de Janeiro: Jorge Zahar.

Heinemann, G. B. B., Chatelard, D. S. (2012). Concepção atual de família: do declínio da função paterna aos novos sintomas. Revista Mal-estar e Subjetividade, 12(3-4), 639-662. Recuperado em http://pepsic.bvsalud.org/scielo.php?script=sci arttext\&pid=S1518$\underline{61482012000200006 \& \operatorname{lng}=p t \& \operatorname{lng}=p t}$

Kovács, M. J., Hwang, E. (2019). Suicídio por contágio e o papel das mídias de comunicação em massa. Revista M. Estudos Sobre a Morte, Os Mortos E O Morrer, 4(7), 77-100. https://doi.org/10.9789/2525-3050.2019.v4i7.77-100

Lacan, J. (1987). O Mito Individual do Neurótico. Lisboa: Assírio \& Alvim. (Originalmente publicado em 1953).

Lacan, J. (2005). O seminário, livro 10: a angústia. Rio de Janeiro: Jorge Zahar. (Originalmente publicado em 1962-1963).

Lacan, J. (2008). O seminário, livro 16: De um Outro ao outro. Tradução de Vera Ribeiro. Rio de Janeiro: Jorge Zahar. (Originalmente publicado em 1968-1969)

Lacan, J. (2008). O Seminário, livro 11: os quatro conceitos fundamentais da psicanálise. Rio de Janeiro: Jorge Zahar. (Originalmente publicado em 1964)

Loureiro P. R., Moreira T., Sachsida, A. (2013). Os efeitos da mídia sobre o suicídio: uma análise empírica para estados brasileiros. Rio de Janeiro: IPEA.

Macedo, M. M. K., Werlang, B. S. G. (2007). Trauma, dor e ato: o olhar da psicanálise sobre uma tentativa de suicídio. Ágora: Estudos em Teoria Psicanalítica [online], 10(1), 86-106. https://doi.org/10.1590/S1516-14982007000100006

Minois, G. (2018). História do suicídio: a sociedade ocidental diante da morte voluntária. Tradução de Fernando Santos. São Paulo: Editora Unesp.

Nasio, J.-D. (1997). Lições sobre os 7 conceitos cruciais da psicanálise. Rio de Janeiro: Zahar.

Oliveira, H. M. de., Hanke, B. C. (2017). Adolescer na contemporaneidade: uma crise dentro da crise. Ágora: Estudos em Teoria Psicanalítica [online], 20(2), 295-310. https://doi.org/10.1590/1809-44142017002001

Ons, S. (2018). Tudo o que você precisa saber sobre psicanálise. São Paulo: Planeta do Brasil.

Pagés, C., Ávila, L. A. (2003). Visão freudiana dos grupos: da horda ao vínculo. In W. J. Fernandes, B. Svartman \& B. S. Fernandes (Org.), Grupos e configurações vinculares (Cap. 6, 75-86). Porto Alegre: Artmed.

Papalia, D. E., Feldman, R. D. (2013). Desenvolvimento Humano (12. ed). Porto Alegre, RS: Artmed. 
Phillips, D. (1974). The influence of suggestion on suicide: Substantive and theoretical implications of the Werther effect. American Sociological Review.

Prodanov, C. C., Freitas, E.C. (2013). Metodologia do trabalho científico: métodos e técnicas da pesquisa e do trabalho acadêmico. 2. ed. Novo Hamburgo: Feevale.

Quinet, A. (2009). Psicose e laço social: esquizofrenia, paranoia e melancolia. Rio de Janeiro: Zahar.

Roudinesco, E. (1998). Dicionário de Psicanálise. Rio de Janeiro: Zahar.

Sousa, K. A., Ferreira, M. G. S. G., Coelho, E, F. (2020). Multidisciplinary health care in cases of childhood suicidal ideation: operational and organizational limits. Revista Brasileira de Enfermagem, 73, e20190459. https://doi.org/10.1590/0034-7167-2019-0459

Teixeira, S. M de O, Souza, L. E. C, Viana, L. M. M. (2018). O suicídio como questão de saúde pública. Revista Brasileira em Promoção de Saúde [online], 31(3), 1-3. https://doi.org/10.5020/18061230.2018.8565

Valas, P. (2001). As dimensões do gozo: do mito da pulsão à deriva do gozo. Rio de Janeiro: Zahar.

Viola, D. T. Dutra, Vorcaro, Â. M. R. (2018). A adolescência em perspectiva: Um exame da variabilidade da passagem à idade adulta entre diferentes sociedades. Psicologia: Teoria $e$ Pesquisa [online], 34, e3448. https://doi.org/10.1590/0102.3772e3448

World Health Organization (WHO). (2014). Preventing suicide: a global imperative. Recuperado em http://www.who.int/mental health/suicide-prevention/exe summary english.pdf?ua=1

World Health Organization (WHO). (2018). World Health Statistics 2018: monitoring health for the SDGs, sustainable development goals. Recuperado em http://apps.who.int/iris/bitstream/handle/10665/272596/9789241565585-eng.pdf

Zafiropoulos, M. (2018). Lacan e Lévi-Strauss ou o retorno a Freud (1951-1957). Tradução de Clóvis Marques. (1. ed.). Rio de Janeiro: Civilização Brasileira.

Zanette, C. A., Kern, C., Losso, A. R, da S., Amboni, G. (2020). Tentativa de suicídio na adolescência: perspectiva psicanalítica. Rev. Inova Saúde, Criciúma/SC, 10(1), 103-122. http://dx.doi.org/10.18616/inova.v10i1.2561

Zizek, S. (2009). Violência. Lisboa: Relógio D'água. 